serotonin in the striatum. In the light of these findings and our present clinical finding it seems reasonable to conclude that midbrain tremor is most probably due to combined interruption of the cerebellofugal pathway, the rubrospinal tract, and the ascending monoaminergic nervous pathways.-We are, etc.,

T. FUJIEDA

T. YAMAUCHI

S. TAKAHASHI

Department of Psychiatry and Neurology,

Hokkaido University School of Medicine,

Sapporo, Japan

T. MOROJI

Division of Psychopharmacology,

Tokya, Japan

W., and Hornykiewicz, O., Wiener

2 kl nische Wochenschrift, 1961, 73, 787. L. M., New England fournal of Medicine, 1967, 276, 374.

Boucher, R., and Carabin, S., Brain, 1966, 89, 37.

\section{Effect of Alpha-blocking Drugs in Asthma}

SIR,-The article by Dr. W. C. Alston and others (19 January, p. 90) in precise terms suggests a reversible "blockade" of "betaadrenoceptors" in a mixed leucocyte population in peripheral venous blood in patients with respiratory allergy during acute asthmatic exacerbations. Data obtained from our work on the anti-anaphylactic effect of catecholamines, particularly the inhibition of mediator release, ${ }^{1}$ also suggested this possibility, though obviously in a context completely different from that of the effect of these mediators on "target organs" such as bronchial smooth muscle in asthma, which has been suggested by Szentivanyi. ${ }^{2}$

We have been investigating the possibility of a defect either at the beta-receptor leve or at some step beyond the receptor, including the adenylate (adenyl) cyclase system. Though, in general, we have not found significant differences between normal subjects and allergic asthmatics, whether they were investigated during acute exacerbations or not, we have come across a few patients whose follow-up suggested a relationship between clinical aspects of the disease and the ability of blood leucocytes to respond to isoprenaline by increasing the formation of cyclic 3', 5'-adenosine monophosphate. One outstanding example was a patient with immediate-type allergy to the house dust mite, Dermatophagoides pteronyssinus, who had been under the care of Dr. Monica McAllen since 1967, during which time he had repeatedly undergone various investigations, ${ }^{34}$ including a leucocyte histamine release test. Since 1969 he has been on lowantigen-dosage hyposensitization therapy. His leucocyte response to allergen challenge, which was very strong, remained unchanged until June 1973, when this response completely disappeared. This was associated with disappearance of response to challenge with various anti-human-immunoglobulin sera, including anti-IgE, and it occurred despite an increase in total serum IgE and allergenspecific IgG antibody. The disappearance of leucocyte response was associated with a remarkable increase in the ability of these cells to form increased amounts of cyclic adenosine monophosphate (AMP) in response to isoprenaline. Thus the presence of $8 \times 10^{-5} \mathrm{M}$ isoprenaline cyclic AMP formation rose from $120 \%$ (compared with control values) to $270 \%$. To us it seems difficult to explain all these findings on the basis of "blockade" of beta-adrenoceptors.-We are, etc.,

E. S. K. ASSEM

Department of Pharmacology, SABINA PATERSON

University Colleg

Assem, E. S. K., and Schild, H. O., International Archives of Allergy, 1971, 40, 576

2 Szentivanyi, A., Journal of Allergy, 1968, 42, 203. Medical fournal, 1970, 2, 504.

Assem, E. S. K., and McAllen, M. K., Clinical Allergy, 1973, 3, 161.

\section{Analgesics and the Kidney}

SIR,-It is Dr. R. A. Axelsen and Dr. A. F. Burry's interpretation of the pathology of analgesic renal disease (29 December, p. 784) that does not accord with observable and recorded facts. For instance, Nordenfelt and Ringertz's series ${ }^{1}$ consisted of 30 patients who consumed large amounts of analgesic preparations and subsequently died in renal failure. Twenty-three patients came to necropsy; in eight there was moderate or advanced renal contraction without renal papillary necrosis and in four more there was advanced renal contraction with necrosis of only one papilla. Burry ${ }^{2}$ was concerned to show that renal papillary necrosis evolved progressively from minor to major lesions and that renal cortical damage followed the major lesions. Mean kidney weight was, however, less for intermediate than for total renal papillary necrosis. Total renal papillary necrosis was found three times as frequently in females as in males and its maximum incidence was in age group 40-50, only one patient being older than 70 years. Only one patient less than 50 years old showed the earlier lesions and their highest incidence was in patients older than 70 years, the sex incidence being equal. While all types of lesions are found in age group 50-70, these differences in incidence for age and sex weaken the hypothesis that the lesions are necessarily part of a single progressive pathological process. It has yet to be suggested that analgesics could cause rejuvenation or sexual transmutation.

The real difficulty confronting Drs. Axelsen and Burry arises from their preoccupation with the clinical aspects of analgesic nephropathy. This has led them to neglect the wider problem of the effects of certain organic molecules upon mammalian renal tissue and to accept experimental findings only when these are consonant with their interpretations of clinical phenomena. The observations ${ }^{3}$ which they dismiss so summarily constitute the only body of evidence that compounds related to phenacetin may be nephrotoxic, and the experimental model is designed to enable detailed studies to be made of the interaction of these compounds and renal tissue.-We are, etc.,

I. C. Calder

C. C. FUNDER

K. N. HAM

J. D. TANGE

Departments of Chemistry and Pathology,

University of Melbourne,

Victoria, Australia

Nordenfelt, O., and Ringertz, N., Acta Medica Scandinavica, 1961, 170, 385 .
3 Calder, I. C., Funder, C. C., Green, C. R., Ham, fournal, 1971, 4, 518 .

\section{One Thousand Vasectomies}

SIR,-I am surprised that Dr. M. Altman is shocked (2 February, p. 198). To describe one's reaction to a professional opinion as one of shock implies a tone of high moral fervour which is unbecoming to a subject from which as much emotion as possible should be removed. It is clear that Dr. Altman and I have completely opposite points of view on the purpose of vasectomy. $\mathrm{He}$ is concerned with a mass number of operations in an attempt presumably to influence a national birth rate; this is the system as is practised in underdeveloped countries and is fitting to their needs. I am concerned with a small group of individually treated patients in whom my main responsibility is to prevent any possibility of pregnancy. I feel no guilt for destroying $7.5 \mathrm{~cm}$ of the vas because I have warned my patients adequately in advance and they all accept this.

Dr. Altman bases part of his criticism on the fact that the lesser operation may be reversible. I thought that I had made it clear in my letter that equivocation in this matter was unsatisfactory and could be misleading to the patient. Amelar" states: "In a survey of American urologists a suocess rate of $45 \%$ has been reported for 420 vasovasostomies . . . but there is a world of difference between sperm appearing in the ejaculate and the occurrence of pregnancy." Blandy ${ }^{2}$ has gone on record as saying that "few surgeons will expect more than a $25 \%$ success rate from attempts to re-join a divided vas and if a husband asks for an operation which can be undone again, it is best to decline to operate under these conditions." Hanley, ${ }^{3}$ who is a known proponent of a potentially reversible vasectomy operation, reported on his results of vasal anastomosis following vasectomy in 35 patients. In 27 of these cases sperm appeared in the ejaculate, but only eight pregnancies resulted-that is, the overall success rate is 35 cases was of the order of $23 \%$. It would seem, therefore, that until a fool-proof technique of reversibility has been tried and proved, the concept of a potentially reversible vasectomy is chimerical. I believe that I have a duty to inform my patients that the operation is permanently irreversible and to do my best to ensure that the operation fulfils these requirements.-I am, etc.,

\section{G. SCHRAIBMAN}

The Infirmary

\section{Rochdale} 1 Amelar, R. D., Infertility in Men, p. 130.
Philadelphia, Davis, 1966.
2 Blandy, J. D., in Operative Surgery, ed. C. Rob
and R. Smith, 2nd edn, vol. 12, p. 388. Lon-
don, Butterworths, 1970.
3 Hanley, H. G., British fournal of Urology, 1972,
44, 721.

\section{Brain Damage after Lithium and Phenytoin}

SIR,-In their communication on "Permanent Brain Damage after Lithium Intoxication" (15 December, p. 673) Drs. P. Juul-Jensen and $M$. Schou describe two cases of persistent ataxia after overdosage with lithium plus phenytoin in the first 
instance and with lithium plus dehydration in the second. They make the statement that "permanent after effects of phenytoin challenged.

In this department we have had a patient with dysarthria, nystagmus, and ataxia whose serum phenytoin level was $36 \mu \mathrm{g} / \mathrm{ml}$ and who failed to lose her cerebellar signs when treatment was stopped. There have been several such reports. ${ }^{12}$ Utterback $^{1}$ and Kokenge et al. ${ }^{2}$ went on to describe overdosing experimental animals with phenytoin and producing fall-out of Purkinje cells from the cerebellum. Kokenge et al. found consistently higher concentrations of the drug in the stem and cerebellum than in the rest of the brain.

$D^{2}{ }^{3}$ has questioned these effects of phenytoin. He has also overdosed animals but found no difference in their Purkinje cells as compared with controls. $\mathrm{He}$ also studied the brains of 32 epileptics. Two of them had never had phenytoin and had normal cell counts. The serum phenytoin levels of the remainder were not known and their antemortem cerebellar state is not mentioned. Diminished numbers of Purkinje cells were found in some patients. In this poisoning are not known." This must be

small series there seemed to be a better correlation with fit frequency than with the dose of phenytoin. However, it is too premature to conclude that this fall-out of cells is due to frequent seizures and presumed anoxia alone. Different individuals have very different serum levels of phenytoin, even when on the same oral dose. Patients with severe epilepsy are likely to be on larger doses of this drug, as well as being on other anti-convulsants-for example, sulthiamewhich increase its serum level.

The great majority of epileptics who become ataxic on phenytoin recover on its withdrawal. Perhaps phenytoin toxicity sensitizes the Purkinje cells so that in an individual who suffers additional insultsfor example, frequent fits with anoxiathey are permanently darmaged. The same may be true of lithium.-I am, etc.,

Department of Neurology,

Burmingham

1 Utterback, R. A., Archives of Neurology and Prychiatry, 1958, 80, 180 .
Kokenge, R., Kutt, H., and McDowell, F., Neurology, 1965, 15, 823 Dam, M., Acta Neurologica Scandinavica, 1972,
48, Suppl. 49.

\section{Malaria}

SIR,-If an aggrieved author can display his disappointment with a review of his book (Mr. R. M. Pinder, 16 February, p. 289), then a reviewer accused of unfairness and arrogance may perhaps claim the right to reply and to justify his views.

As I said before (10 November, p. 364) $\mathrm{Mr}$. Pinder's outline of the chemistry and pharmacology of antimalarial compounds is the most satisfactory part of his book and he should have limited himself to things he appears to know. It is not unfair on the part of the reviewer to select three out of nine chapters for detailed analysis if these chapters show that the author is not conversant with the subjects that come under this unbalanced book's misleading main title. Like the proverbial curate's egg, several parts of the book are good.

And now may I deal, one by one, with the points made by $\mathrm{Mr}$. Pinder in his letter, though other mis-statements or errors could be found in his book?

(1) The reference to the possibility of altering the man-biting habits of Anopheles, so naively quoted from one of my papers, should have been understood in its context of the study of precipitin tests on blood meals of mosquitoes. A hypothetical reflection of 10 years ago has been elevated by $\mathrm{Mr}$. Pinder into a feasible method of malaria control.

(2) The reference to proguanil shows the author's lack of awareness of the difference between prophylaxis sensu stricto and mass drug administration. For causal prophylaxis of malaria in groups of non-immunes proguanil is still a most useful drug. For mass drug administration in semi-immune populations already infected with malaria proguanil (as also pyrimethamine) alone is not advisable.

(3) It is emphatically not true that the greater the use of chloroquine in the field the more rapidjy resistance develops. There are many exceptions to this rule and chloroquine resistance appeared in many areas (for example, Colombia and Malaysia) where chloroquinized salt has never been used. It did not appear in Africa even though the drug has been in use in several countries (Madagascar, Cameroun) for many years.
(4) On the formation of gametocytes $\mathrm{Mr}$. Pinder is woefully wrong. Gametocytes may originate from the merozoites of e-e schizonts only in the sub-genus Haemamoeba and in Plasmodium berghei, which do not comprise human plasmodia. In the sub-genera Plasmodium and Laverania of malaria parasites of man one or more generations of schizogony in the blood are necessary before changing to sexual forms (Garnham, ${ }^{2}$ p. 36 ).

(5) Multiple infection of erythrocytes undoubtedly occurs more commonly with $P$. falciparum than with $P$. vivax. Why did not the author stress this important diagnostic feature between the two species?

(6) Quotation from Neva's review ${ }^{3}$ does not help. There are no malaria toxins comparable to bacterial endotoxins, and plasmodial infection normally produces a considerable degree of immunity.

(7) The population of East Africa and the Congo is not (repeat not) infected with $P$. malariae in totc. While in some localities of East Africa the prevalence of $P$. malariae was found to be $90 \%$ or over, no one has ever shown that such prevalence is today widely spread.

(8) On gametocytocidal action of pyrimethamine Mr. Pinder says on p. 42, lines 8-9 of his book: "Primaquine and pyrimethamine (my italics) seem to be the only drugs with a true gametocytocidal action." This is not so.

(9) I can only regret that the author of a book on malaria can maintain that the lack of morpholcgical distinction between $P$. falciparum of man and $P$. reichenowi of higher African apes suggests that these are the same parasites. This is another example of his imperfect acquaintance with the parasitology of malaria.

(10) I am glad that the error concerning sulphonamides as causal prophylactic drugs has been admitted by the author.

For a favourable review of his book $\mathrm{Mr}$. Pinder advises the readers to consult the pages of a journal to the relevant issue of which no reference is given. His accusation that my review in your journal was unfair may be countered by another appraisal published in an equally distinguished medical journal: "The sections on epidemiological, parasitological, and clinical aspects of malaria suggest that the author ... is writing on matters of which he has little personal experience. ... It is difficult to understand why this book was ever thought necessary." With this opinion I wholly and unrepentantly agree.-I am, etc.,

\section{J. BRUCE-CHWATT}

Ross Institute of Tropical Hygiene,

London School of Hygiene and Tropical Medicine, London W.C.1

1 Bruce-Chwatt, L. J., Garrett-Jones, C., and Weitz, B., Bulletin of the World Health Organization,

2 Garnham, P. C. C., Malaria Parasites and Other Haemosporidia. Oxford, Blackwell, 1966.

Neva, F. A., New England fournal of Medicine, Lancet, $1973,2,1242$.

${ }^{*}{ }^{*}$ This correspondence is now closed. -ED., B.M.7.

A Professional Responsibility?

SIR,-Concerning Dr. M. T. Sweetnam's letter (16 February, p. 289) I would like to make the following comments.

The Council of Management of the Cameron Fund did discuss the whole question of the provision of residential care. Quite apart from the question of desirability, it was not financially possible for two reasons. Firstly, the drop in investment income consequent upon the "locking up" of a large capital sum and, secondly, the estimated cost of upkeep.

With regard to voluntary levies, many local medical committees already contribute to the Cameron Fund, and for this we are grateful. The B.M.A. does publish a booklet giving an account of the various medical charities, together with a covenant form. If a substantial proportion of the profession would make an annual covenant of as little as £5 the resulting sum would not only greatly augment the disbursable moneys of the various charities but also make such a project as a residential nursing home feasible.

It must be admitted that appeals in the past have been disappointing, but one hopes for the future. Perhaps Dr. Sweetnam has set the ball rolling. I hope so.-I am, etc.,

\section{B. HOLDEN}

Tavistock House North, Chair
Tavistock Square, London W.C.1

\section{Consultant Discontent}

SIR,-Your leading article (9 February, p. 211) attacking the existence of the Regional Hospitals' Consultants and Specialists Association, together with the letter from Mrs. Jean G. C. Turner in the same issue (p. 247), seems particularly inappropriate at this time. You threaten the dangers which will befall the senior hospital doctors following the upsurgence of an alternative association. Perhaps the B.M.f. regards the continuing existence of the B.M.A. as the profession's sole representative as important. But what the R.H.C.S.A. regards as infinitely more important is that the high standards of British hospital medicine are preservedand this can be assured only by creating terms and conditions of service which will attract doctors of the highest calibre into the consultant ranks. That this is not being achieved is now admitted by B.M.A. leaders.

Of course we wish for unity, but there is not one shred of evidence to show that this 